\title{
Ejaculados individuais e pools de sêmen: diferenças em condições experimentais
}

\author{
[Individual ejaculates and pooled semen: differences under experimental conditions] \\ R.M. Mascarenhas ${ }^{1}$, P.R. Xavier ${ }^{1}$, A.P. Marques Júnior ${ }^{2}$ \\ ${ }^{1}$ Aluna de pós-graduação - EV-UFMG - Belo Horizonte, MG \\ ${ }^{2}$ Escola de Veterinária - Universidade Federal de Minas Gerais - EV-UFMG - Belo Horizonte, MG
}

\section{RESUMO}

Avaliaram-se ejaculados caninos individuais e pools de sêmen submetidos a dois tratamentos de renovação do meio diluidor. Sêmen de seis cães foi coletado, na forma de ejaculados individuais e pools de sêmen, diluído na proporção de 1:1 em meio Tris-Gema, centrifugado a 500g/10min, e o pellet ressuspendido até concentração final de $50 \times 10^{6}$ espermatozoides $/ \mathrm{mL}$. O sêmen foi resfriado a $0,26^{\circ} \mathrm{C} / \mathrm{min}$, entre 37 e $16^{\circ} \mathrm{C}$, e $0,08^{\circ} \mathrm{C} / \mathrm{min}$, entre 16 a $8^{\circ} \mathrm{C}$, e mantido em geladeira a $5^{\circ} \mathrm{C}$ por 14 dias. No Tratamento 1, o meio diluidor foi renovado a cada seis dias, e no Tratamento 2 aos 12 dias. O sêmen foi avaliado, a cada 48 horas, quanto à motilidade espermática, utilizando-se o Sperm Class Analyser® (SCA), e quanto à integridade de membranas pelo teste hiposmótico e coloração com PI/CFDA. A formação de pools de sêmen simplificou sua manipulação, principalmente com relação ao aumento do volume da amostra disponível; no entanto, resultados obtidos a partir de ejaculados individuais mostraram diferenças entre tratamentos, não identificadas nos pools de sêmen.

Palavras-chave: cão, sêmen pooling, criopreservação

\begin{abstract}
Individual ejaculates and pooled dog semen submitted to two treatments of medium exchange were evaluated. Semen was collected from six dogs, as individual ejaculates and pooled semen, diluted in a 1:1 ratio in Tris-Yolk medium, centrifuged at 500g/10min and ressuspended to the final concentration of $50 \times 106 \mathrm{sptz} / \mathrm{mL}$. The samples were cooled at rates of $0.26^{\circ} \mathrm{C} / \mathrm{min}$ between 37 and $16^{\circ} \mathrm{C}$, and $0.08{ }^{\circ} \mathrm{C} / \mathrm{min}$ from 16 to $8^{\circ} \mathrm{C}$, and then kept in a refrigerator for 14 days. In Treatement 1 medium was exchanged every six days and in Treatment 2 after twelve days. The cooled samples were evaluated every 48 hours for sperm motility using the Sperm Calss Analyser ${ }^{\circledR}(S C A)$, and membrane integrity with hiposmotic swelling test and PI/CFDA stain. Pooled semen was easier to handle, mainly considering the decreased work due to volume. When submitted to medium exchange, pooled semen behaved similarly to individual ejaculates; however, results obtained from individual ejaculates showed differences between treatments, which were not apparent in pooled semen results.
\end{abstract}

Keywords: dog, pooled semen, cryopreservation

\section{INTRODUÇÃO}

Entre as espécies domésticas, o cão é uma das que apresenta menor produção espermática diária e menor número de espermatozoides por ejaculado (Threlfall, 2003), características que podem limitar o delineamento de experimentos, tornando inviável submeter o mesmo ejaculado a diversos tratamentos ou realizar análises que demandem maior volume de material. No intuito de aumentar o volume de material, vários trabalhos na área de resfriamento de sêmen canino utilizam como unidade experimental pools de sêmen. Alguns pesquisadores argumentam que a utilização de pools de sêmen minimiza o efeito do indivíduo e, consequentemente, melhora as características do sêmen, os parâmetros estatísticos e a

Recebido em 28 de outubro de 2012

Aceito em 5 de setembro de 2013

E-mail: rebecavet01@gmail.com 
confiabilidade dos resultados (Ponglowhapan et al., 2004; Verstegen et al., 2005; Shahiduzzaman e Linde-Frosberg, 2007; Lopes et al., 2009; Michael et al., 2009).

Objetivou-se comparar os resultados de motilidade espermática e integridade de membranas obtidos de ejaculados caninos resfriados na forma de ejaculados individuais e pools de sêmen, submetidos à renovação do meio diluidor a cada seis dias ou após 12 dias de resfriamento.

\section{MATERIAL E MÉTODOS}

O experimento foi realizado após o projeto ter sido aprovado pelo Cetea/UFMG 009/2011. Foram utilizados seis cães, dois da raça Labrador e dois da raça Shar Pei, com idade entre três e cinco anos, provenientes de canil particular. Foram selecionados cães que apresentavam motilidade espermática acima de $70 \%$ e menos de $30 \%$ de espermatozoides morfologicamente anormais no ejaculado (Johnson et al., 2001).

A segunda fração do ejaculado foi coletada pelo método de manipulação digital do pênis (LindeForsberg, 2001). Para avaliação de ejaculados individuais, foi realizada, em um só dia, uma coleta de sêmen de cada um dos seis cães, e cada ejaculado foi tratado como uma unidade experimental. Para avaliação dos pools de sêmen, também foram utilizados seis pools, sendo cada um deles formado por seis ejaculados completos, um de cada cão. Para formação de cada pool foi coletado um ejaculado de cada cão, sendo que todos os ejaculados formadores de um pool foram coletados no mesmo dia. Os pools foram formados com intervalo de dois a três dias entre si. Cada pool foi tratado como uma unidade experimental.

O sêmen foi diluído na proporção de 1:1 em meio Tris-Gema (Rota et al., 1995) e centrifugado a $500 \mathrm{~g}$ por $10 \mathrm{~min}$. Após a centrifugação, o pellet foi ressuspendido em meio Tris-Gema até a concentração final de $50 \times 10^{6}$ espermatozoides $/ \mathrm{mL}$. O sêmen foi resfriado, em caixa de poliestireno contendo gelo reutilizável, à taxa de $0,26^{\circ} \mathrm{C} / \mathrm{min}$ entre $37 \mathrm{e}$ $16^{\circ} \mathrm{C}$, e $0,08^{\circ} \mathrm{C} / \mathrm{min}$ entre 16 e $8^{\circ} \mathrm{C}$. Após resfriado, o sêmen foi mantido em geladeira a $5^{\circ} \mathrm{C}$ por 14 dias. Cada ejaculado, ou cada pool de ejaculados, foi dividido em dois tratamentos. No
Tratamento 1 o meio diluidor foi renovado a cada seis dias, e no Tratamento 2 o meio diluidor foi renovado após 12 dias. Para a renovação do meio diluidor, igual volume de meio recémpreparado foi resfriado em geladeira por duas horas. Em seguida, o sêmen diluído foi centrifugado sob refrigeração $\left(5^{\circ} \mathrm{C}\right)$, a $500 \mathrm{~g}$ por 10min. O pellet foi ressuspendido em meio recém-preparado ou no meio original conforme o tratamento experimental.

O sêmen resfriado foi avaliado, a cada 48 horas, quanto à motilidade espermática e à integridade de membranas. Para avaliação da motilidade espermática, foi utilizado o Sperm Class Analyser® (SCA), versão 4.0, da Microptic (C) (Barcelona, Espanha). As amostras resfriadas foram aquecidas em banho-maria a $37^{\circ} \mathrm{C}$ por $2 \mathrm{~min}$, uma gota de $5 \mu \mathrm{L}$ foi colocada entre lâmina e lamínula, previamente aquecidas a $37^{\circ} \mathrm{C}$ e acondicionadas ao SCA. Os espermatozoides foram classificados nas seguintes categorias: móveis rápidos progressivos, móveis progressivos totais e móveis totais. Foram avaliadas também a retilinearidade (STR) e a linearidade (LIN) do movimento espermático.

A integridade funcional da membrana plasmática da cauda dos espermatozoides foi avaliada pelo teste hiposmótico (HO), segundo a técnica descrita por Kumi-Diaka (1993), utilizando-se solução de 60 mosmol de frutose em água destilada. A porcentagem de células reativas ao teste hiposmótico foi corrigida segundo a fórmula proposta por Melo e Henry (1999).

A integridade estrutural da membrana plasmática da cabeça e do acrossoma dos espermatozoides resfriados foi avaliada pela técnica da fluorescência, adotando-se os fluorocromos diacetato de carboxifluoresceína (CFDA) e o iodeto de propídio (IP), segundo o protocolo de Harrison e Vickers (1990), modificado por Zúccari (1998). Os espermatozoides foram classificados como: íntegros; lesados e semilesados.

O delineamento experimental foi em blocos ao acaso com parcelas subdivididas, sendo o cão ou o pool de sêmen o bloco, o tratamento a parcela, e o dia a subparcela. As variáveis apresentaram distribuição normal e foram comparadas pela ANOVA, utilizando-se o teste de Tukey-Kramer com nível de significância de 5\%, no programa 
SAS, versão 2008. Os resultados foram expressos como média \pm desvio-padrão.

\section{RESULTADOS E DISCUSSÃO}

$\mathrm{Na}$ Tab. 1, que demonstra o efeito imediato da renovação do meio diluidor sobre a motilidade espermática, observa-se que a motilidade manteve-se constante nas amostras que sofreram renovação do meio no sexto e no $12^{\circ}$ dia, tanto nos ejaculados individuais quanto nos pools de sêmen. A centrifugação e a ressuspensão no meio original levaram à queda todos os parâmetros de motilidade, tanto nos pools de sêmen quanto nos ejaculados individuais, com exceção da porcentagem de espermatozoides rápidos progressivos, cujos valores observados nos pools antes e após a centrifugação e a ressuspensão no meio original não diferiram.

A partir do dia 6, os valores médios dos parâmetros de motilidade espermática, tanto nos pools de sêmen quanto nos ejaculados individuais, foram superiores no Tratamento 1 (Tab. 2). No entanto, só se observou diferença estatística entre os tratamentos nos resultados obtidos de ejaculados individuais, cuja média de espermatozoides móveis totais foi superior no Tratamento 1 nos quatro dias seguintes à renovação do meio (Tab. 2).

Tabela 1. Média \pm desvio-padrão da porcentagem de espermatozoides rápidos progressivos, progressivos totais e móveis totais de seis pools de sêmen e seis ejaculados individuais caninos resfriados por 14 dias, antes e após o tratamento de centrifugação e ressuspensão em meio diluidor recém-preparado (T-1: dias 6 e 12; T-2: dia 12), ou centrifugação e ressuspensão no meio diluidor original (T-2: dia 6)

\begin{tabular}{|c|c|c|c|c|c|c|}
\hline & & & $\begin{array}{l}\text { Dia } 6 \text { antes do } \\
\text { tratamento }\end{array}$ & $\begin{array}{l}\text { Dia } 6 \text { após o } \\
\text { tratamento }\end{array}$ & $\begin{array}{c}\text { Dia } 12 \text { antes } \\
\text { do } \\
\text { tratamento }\end{array}$ & $\begin{array}{l}\text { Dia } 12 \text { após } \\
\text { o tratamento }\end{array}$ \\
\hline \multirow{4}{*}{$\begin{array}{c}\text { Rápidos } \\
\text { Progressivos }\end{array}$} & \multirow[b]{2}{*}{$T-1$} & Pool & $43,08 \pm 5,56$ & $40,04 \pm 10,86$ & $5,19 \pm 7,48$ & $3,82 \pm 3,37$ \\
\hline & & $\begin{array}{l}\text { Ejac. } \\
\text { Indiv. }\end{array}$ & $19,17 \pm 7,91$ & $17,85 \pm 6,43$ & $2,21 \pm 4,19$ & $1,83 \pm 3,26$ \\
\hline & \multirow[b]{2}{*}{$T-2$} & Pool & $43,08 \pm 5,56$ & $36,87 \pm 12,74$ & $3,51 \pm 3,99$ & $5,43 \pm 3,95$ \\
\hline & & $\begin{array}{l}\text { Ejac. } \\
\text { Indiv. }\end{array}$ & $19,17 \mathrm{a} \pm 7,91$ & $12,65 b \pm 8,51$ & $1,09 \pm 1,94$ & $1,69 \pm 3,34$ \\
\hline \multirow{4}{*}{$\begin{array}{c}\text { Progressivos } \\
\text { Totais }\end{array}$} & \multirow[b]{2}{*}{$T-1$} & Pool & $64,97 \pm 7,29$ & $57,53+14,91$ & $9,01+10,64$ & $6,67 \pm 4,46$ \\
\hline & & $\begin{array}{l}\text { Ejac. } \\
\text { Indiv. }\end{array}$ & $34,87 \pm 14,72$ & $33,59 \pm 10,11$ & $4,11 \pm 7,91$ & $3,34 \pm 4,52$ \\
\hline & \multirow[b]{2}{*}{$T-2$} & Pool & $64,97 \mathrm{a}+7,29$ & $52,31 b+15,13$ & $5,02+5,60$ & $7,83+5,22$ \\
\hline & & $\begin{array}{l}\text { Ejac. } \\
\text { Indiv. }\end{array}$ & $34,87 \mathrm{a} \pm 14,72$ & $21,1 b \pm 10,93$ & $2,24 \pm 4,56$ & $4,66 \pm 9,12$ \\
\hline \multirow{4}{*}{ Móveis Totais } & \multirow[b]{2}{*}{$T-1$} & Pool & $74,89 \pm 7,47$ & $70,66 \pm 13,55$ & $15,41 \pm 14,50$ & $13,83 \pm 9,24$ \\
\hline & & $\begin{array}{l}\text { Ejac. } \\
\text { Indiv. }\end{array}$ & $57,04 \pm 15,07$ & $55,40 \pm 14,18$ & $9,53 \pm 13,29$ & $9,84 \pm 8,02$ \\
\hline & \multirow[b]{2}{*}{$T-2$} & Pool & $74,89 \mathrm{a} \pm 7,47$ & $62,26 \mathrm{~b} \pm 13,86$ & $12,95 \pm 13,59$ & $17,02 \pm 12,42$ \\
\hline & & $\begin{array}{l}\text { Ejac. } \\
\text { Indiv. }\end{array}$ & $57,04 a \pm 15,07$ & $36,25 b \pm 10,18$ & $4,08 \pm 6,95$ & $8,59 \pm 14,76$ \\
\hline
\end{tabular}

Médias marcadas com letras minúsculas na mesma linha diferem entre si $(\mathrm{P}<0,05)$.

T-1: sêmen submetido à renovação do meio diluidor a cada seis dias.

T-2: sêmen submetido à renovação do meio diluidor após 12 dias.

A renovação do meio diluidor não teve efeito nem sobre o padrão de motilidade dos espermatozoides nem sobre a integridade de membranas espermáticas do sêmen, seja avaliado na forma de pools ou de ejaculados individuais.

No presente trabalho, avaliou-se o efeito da renovação do meio diluidor sobre a qualidade do sêmen de seis cães, sendo o sêmen avaliado na forma de ejaculados individuais e agrupado em pools. Alguns pesquisadores argumentam que a utilização de pools de sêmen facilita sua manipulação, aumentando o volume de material de trabalho e viabilizando algumas análises, além de melhorar os parâmetros estatísticos, eliminando o efeito do indivíduo (Ponglowhapan 
et al., 2004; Verstegen et al., 2005; Shahiduzzaman e Linde-Frosberg, 2007; Lopes et al., 2009; Michael et al., 2009). No presente trabalho, a formação de pools de sêmen facilitou sua manipulação, todavia tanto os desvios-padrão quanto os coeficientes de variação dos resultados obtidos de pools foram semelhantes aos obtidos de ejaculados individuais. Embora os ejaculados individuais e os pools de sêmen tenham reagido de forma semelhante aos tratamentos de renovação do meio diluidor, os primeiros proporcionaram resultados mais claros $\mathrm{e}$ precisos, capazes de estabelecer diferenças entre tratamentos não identificadas nos pools de sêmen.

Tabela 2. Média+desvio-padrão da porcentagem de espermatozoides rápidos progressivos, progressivos totais e móveis totais de seis pools de sêmen e seis ejaculados individuais caninos, resfriados por 14 dias e submetidos a dois tratamentos de renovação do meio diluidor

\begin{tabular}{|c|c|c|c|c|c|c|c|c|c|c|c|c|}
\hline \multirow[b]{3}{*}{ Dias } & \multicolumn{4}{|c|}{ Rápidos Progressivos } & \multicolumn{4}{|c|}{ Progressivos Totais } & \multicolumn{4}{|c|}{ Móveis Totais } \\
\hline & \multicolumn{2}{|c|}{ Pool } & \multicolumn{2}{|c|}{ Ejac. Indiv. } & \multicolumn{2}{|c|}{ Pool } & \multicolumn{2}{|c|}{ Ejac. Indiv. } & \multicolumn{2}{|c|}{ Pool } & \multicolumn{2}{|c|}{ Ejac. Indiv. } \\
\hline & $T-1$ & $T-2$. & $T-1$ & $T-2$ & $T-1$ & $T-2$. & $T-1$ & $T-2$. & $T-1$ & $T-2$. & $T-1$ & $T-2$ \\
\hline 0 & $\begin{array}{c}41,52 \pm \\
12,29\end{array}$ & $\begin{array}{c}41,52 \pm \\
12,29\end{array}$ & $\begin{array}{c}39,90 \pm \\
8,74\end{array}$ & $\begin{array}{c}39,90 \pm \\
8,74\end{array}$ & $\begin{array}{c}73,71 \pm \\
9,75\end{array}$ & $\begin{array}{c}73,71 \pm \\
9,75\end{array}$ & $\begin{array}{c}65,97 \pm \\
9,15\end{array}$ & $\begin{array}{c}65,97 \pm \\
9,15\end{array}$ & $\begin{array}{c}86,80 \pm \\
7,78\end{array}$ & $\begin{array}{c}86,80 \pm \\
7,78\end{array}$ & $\begin{array}{c}86,75 \pm \\
6,50\end{array}$ & $\begin{array}{c}86,75 \pm \\
6,50\end{array}$ \\
\hline 2 & $\begin{array}{c}53,92 \pm \\
5,96\end{array}$ & $\begin{array}{c}53,92 \pm \\
5,96\end{array}$ & $\begin{array}{c}37,04 \pm \\
9,26\end{array}$ & $\begin{array}{c}37,04 \pm \\
9,26\end{array}$ & $\begin{array}{c}80,44 \pm \\
4,54\end{array}$ & $\begin{array}{c}80,44 \pm \\
4,54\end{array}$ & $\begin{array}{c}60,82 \pm \\
13,03\end{array}$ & $\begin{array}{c}60,82 \pm \\
13,03\end{array}$ & $\begin{array}{c}87,20 \pm \\
2,03\end{array}$ & $\begin{array}{c}87,20 \pm \\
2,03\end{array}$ & $\begin{array}{c}82,97 \pm \\
7,89\end{array}$ & $\begin{array}{c}82,97 \pm \\
7,89\end{array}$ \\
\hline 6 & $\begin{array}{c}43,08 \pm \\
5,56\end{array}$ & $\begin{array}{c}43,08 \pm \\
5,56\end{array}$ & $\begin{array}{c}19,17 \pm \\
7,91\end{array}$ & $\begin{array}{c}19,17 \pm \\
7,91\end{array}$ & $\begin{array}{c}64,97 \pm \\
7,29\end{array}$ & $\begin{array}{c}64,97 \pm \\
7,29\end{array}$ & $\begin{array}{c}34,87 \pm \\
14,72\end{array}$ & $\begin{array}{c}34,87 \pm \\
14,72\end{array}$ & $\begin{array}{c}74,89 \pm \\
7,47\end{array}$ & $\begin{array}{c}74,89 \pm \\
7,47\end{array}$ & $\begin{array}{c}57,04 \pm \\
15,07\end{array}$ & $\begin{array}{c}57,04+ \\
15,07\end{array}$ \\
\hline 8 & $\begin{array}{c}35,71 \pm \\
4,41\end{array}$ & $\begin{array}{c}31,27 \pm \\
16,09\end{array}$ & $\begin{array}{c}10,79 \pm \\
6,80\end{array}$ & $\begin{array}{l}8,69 \pm \\
10,91\end{array}$ & $\begin{array}{c}51,59 \pm \\
7,35\end{array}$ & $\begin{array}{c}42,90 \pm \\
17,48\end{array}$ & $\begin{array}{c}20,07 \pm \\
12,16\end{array}$ & $\begin{array}{c}17,17 \pm \\
14,75\end{array}$ & $\begin{array}{c}61,79 \pm \\
10,12\end{array}$ & $\begin{array}{c}54,30 \pm \\
18,46\end{array}$ & $\begin{array}{c}41,17 \mathrm{a} \pm \\
15,75\end{array}$ & $\begin{array}{c}29,07 \mathrm{~b} \pm \\
16,21\end{array}$ \\
\hline 10 & $\begin{array}{c}19,91 \pm \\
14,18\end{array}$ & $\begin{array}{c}19,98 \pm \\
8,47\end{array}$ & $\begin{array}{c}5,38 \pm \\
6,80\end{array}$ & $\begin{array}{c}2,95 \pm \\
4,42\end{array}$ & $\begin{array}{c}30,55 \pm \\
14,52\end{array}$ & $\begin{array}{c}30,42 \pm \\
10,59\end{array}$ & $\begin{array}{c}12,53 \pm \\
13,83\end{array}$ & $\begin{array}{c}6,34 \pm \\
8,38\end{array}$ & $\begin{array}{c}42,27 \pm \\
11,30\end{array}$ & $\begin{array}{c}41,74 \pm \\
12,48\end{array}$ & $\begin{array}{c}26,26 \mathrm{a} \pm \\
17,21\end{array}$ & $\begin{array}{c}10,95 \mathrm{~b} \pm \\
11,64\end{array}$ \\
\hline
\end{tabular}

Médias marcadas com letras minúsculas na mesma linha diferem entre si $(\mathrm{P}<0,05)$

T-1: sêmen submetido à renovação do meio diluidor a cada seis dias.

T-2: sêmen submetido à renovação do meio diluidor após 12 dias.

Embora em uma análise global os resultados obtidos de ejaculados individuais e pools de sêmen tenham evidenciando o mesmo efeito benéfico da renovação do meio sobre a manutenção dos espermatozoides resfriados, os resultados obtidos dos ejaculados individuais foram mais claros e precisos, sendo capazes de estabelecer, em alguns parâmetros de motilidade, diferenças entre tratamentos não identificadas nos pools de sêmen.

$\mathrm{Na}$ formação de pools de sêmen, mais do que agrupamento de espermatozoides, são agrupadas proteínas e outros componentes, cuja interação e efeito sobre a criorresistência espermática ainda não são esclarecidos. Especula-se que algumas proteínas componentes do plasma seminal, como as proteínas com afinidade pela heparina, têm papel fundamental no processo de capacitação espermática e também influenciam a resistência dos espermatozoides à criopreservação, podendo estar relacionadas com as diferenças individuais na criorresistência do sêmen (Manjunath et al., 2002; Moore et al., 2005; Souza et al., 2007). A variabilidade na qualidade do sêmen e na resistência à criopreservação é uma característica inerente à espécie canina (Threlfall, 2003; Kutzler, 2005). Se, por um lado, o agrupamento de ejaculados em pools pode diminuir a variabilidade de respostas e melhorar os parâmetros estatísticos, por outro corre-se o risco de se perderem detalhes individuais relevantes.

Diferenças entre indivíduos na qualidade do sêmen e na resistência à criopreservação é uma característica reprodutiva inerente à espécie canina (Threlfall, 2003; Kutzler, 2005). Se, por um lado, o agrupamento de ejaculados em pools pode eliminar o efeito do individuo e, assim, melhorar os parâmetros estatísticos, por outro corre-se o risco de se perderem informações importantes acerca da variabilidade individual de respostas. 


\section{CONCLUSÃO}

A formação de pools de sêmen simplificou sua manipulação principalmente no que diz respeito ao aumento do volume do material de trabalho. No entanto, embora os resultados obtidos de ejaculados individuais e pools de sêmen tenham evidenciando o mesmo efeito benéfico da renovação do meio sobre a manutenção dos espermatozoides resfriados, os resultados obtidos dos ejaculados individuais foram capazes de estabelecer diferenças entre tratamentos não identificadas nos pools de sêmen.

\section{AGRADECIMENTOS}

À Capes, pela concessão da bolsa de doutorado ao $\mathrm{CNPq}$, pelo suporte financeiro via grant de pesquisador; e a Alexia e Daniel Oliveira do Canil Zou's, pelo apoio na disponibilização dos animais.

\section{REFERÊNCIAS}

HARRISON, R.A.P.; VICKERS, S.E. Use of fluorescent probes to assess membrane integrity in mammalian spermatozoa. J. Reprod. Fert., v.88, p.343-352, 1990.

JOHNSTON, S.D.; KUSTRITZ, M.V.R.; OLSON, P.N.S. Canine and Feline Theriogenology. Philadelphia: W. B. Saunders, 2001. 592 p.

KUMI-DIAKA, J. Subjecting canine semen to hypoosmotic test. Theriogenology, v.39, p.1279-1289, 1993.

KUTZLER, M.A.; Semen collection in the dog. Theriogenology, v.64, p.747-754, 2005.

LINDE-FORSBERG, C. Intra-uterine insemination in the dog using the scandinavian trans-cervical catheter and a comparison with other methods, 2001. Disponível em: <http://www.ivis.org/advances/ Concannon/linde/chapter.asp?LA=1>. Acessado em: 12/01/2009.

LOPES, G.; SIMÕES, A.; FERREIRA, P. et al. Differences in preservation of canine chilled semen using different transport containers. Anim. Reprod. Sci., v.112, p.158-163, 2009.
MANJUNATH, P.; NAUC, V.; BERGERON, A. et al. Major proteins of bovine seminal plasma bind to the low-density lipoprotein fraction of hen's egg yolk. Biol. Reprod., v.67, p.1250-1258, 2002.

MELO, M.I.V.; HENRY, M. Teste hiposmótico na avaliação do sêmen equino. Arq. Bras. Med. Vet. Zootec., v.51, p.71-78, 1999.

MICHAEL, A.J.; ALEXOPOULOS, C.; PONTIKI, E.A. Effect of antioxidant supplementation in semen extenders on semen quality and reactive oxygen species of chilled canine spermatozoa. Anim. Reprod. Sci., v.112, p.119-135, 2009.

MOORE, A.I.; SQUIRES, E.L.; GRAHAM, J.K. Effect of seminal plasma on the cryopreservation of equine spermatozoa. Theriogenology, v.63, p.23722381, 2005.

PONGLOWHAPAN, S.; ESSÉN-GUSTAVSSON, B.; LINDE-FORSBERG, $C$. Influence of glucose and fructose in the extender during long-term storage of chilled canine semen. Theriogenology, v.62, p.14981517,2004

ROTA, A.; STRÖM, B.; LINDE-FORSBERG, C. Effects of seminal plasma and three extenders on canine semen stored at $4^{\circ} \mathrm{C}$. Theriogenology, v. 44 , p.885-900, 1995.

SHAHIDUZZAMAN, A.K.; LINDE-FORSBERG, C. Induced immobility during long-term storage at +5 degrees $\mathrm{C}$ does not prolong survival of dog spermatozoa. Theriogenology, v.68, p.920-933, 2007.

SOUZA, F.F.; BARRETO, C.S.; LOPES, M.D. Characteristics of seminal plasma proteins and their correlation with canine semen analysis. Theriogenology, v.68, p.100-106, 2007.

THRELFALL, W.R. Semen Collection and Evaluation. In: ROOT KUSTRITZ, M.V.: Small Animal Theriogenology. Missouri: Butterworth Heinemann, 2003. p.97-123.

VERSTEGEN, J.P.; ONCLIN, K.; IGUER-OUADA, M. Long-term motility and fertility conservation of chilled canine semen using egg yolk added Trisglucose extender: In vitro an in vivo studies. Theriogenology, v.64, p.720-733, 2005.

ZÚCCARI, C.E.S.N. Efeito da criopreservação sobre a integridade estrutural da célula espermática equina. 1998. 118F. Tese (Doutorado em Reprodução Anim.) - Faculdade de Medicina Veterinária e Zootecnia, Campus Botucatu, Universidade Estadual Paulista, Botucatu, SP. 